\title{
CONSELHOS GESTORES E O PROCESSO DE DESCENTRALIZAÇÃO
}

\author{
Cátia W. Lubambo
}

HeNRique G. Coutinho

\begin{abstract}
Resumo: O artigo focaliza a criação de conselhos gestores, destacando as Comissões Municipais de Emprego - CME, no estado de Pernambuco, no intuito de desvendar as condições políticas que permeiam a institucionalização da participação. Os critérios de preferência nas homologações das CMEs foram pesquisados a partir de um modelo de análise multivariada.

Palavras-chave: participação; programas sociais; conselhos gestores municipais.
\end{abstract}

Abstract: This article focuses the creation of management councils, highlighting the Employment Municipal Commissions - CME, in the State of Pernambuco, in order to reveal the political conditions imposed to their institutionalization. The selection criteria to approve the CMEs are determined by a multivariate analysis model. Key words: participation; social programs; management municipal councils.

$\mathrm{N}$ ão existem dúvidas sobre o fato de os municípios estarem assumindo maior autonomia e mais responsabilidade na provisão de bens e serviços públicos (ainda que de forma seletiva e na medida de suas possibilidades). Contudo, como explicar (teórica e empiricamente) a evidência de alguns governos locais estarem se destacado mais que outros?

Fragilmente balizado, o debate público se mantém sob uma forte polarização: de um lado, aqueles que apostam no fortalecimento dos governos locais como um processo positivo para a democracia e a eficiência alocativa do setor público e, de outro, aqueles que sustentam que o desempenho da gestão local estaria, em princípio, obstruído por inúmeras razões que remetem de maneira geral à incapacidade político-institucional dos municípios - fragilidade financeira; reduzida capacidade organizacional; tradição de práticas clientelistas ou ausência de um capital social aprimorado capaz de atuar como partícipe de uma gestão social.

Concretamente, as gestões municipais têm se sucedido, ostentando variados desempenhos e apresentando di- ferentes resultados, sob a aprovação ou a desaprovação dos cidadãos. Algumas conclusões sobre o que determina a aprovação de um governo local pelos eleitores apontam a implementação de políticas sociais de educação e saúde como fator preponderante (LUBAMBO, 2000), ao mesmo tempo em que sugerem que as investigações devem prosseguir para analisar as reais condições político-institucionais de tais realizações no âmbito dos municípios. Por exemplo, existe quase uma unanimidade em torno da idéia de que a participação concreta dos segmentos populares no processo decisório é condição básica para efetivação da gestão e, dessa maneira, os recursos seriam destinados com mais eficiência e seu controle seria o mais amplo possível. A abertura de novos canais de comunicação entre a sociedade civil e o poder político local é entendida, assim, como instrumento fundamental da gestão pública, evidenciando inusitados aspectos da dinâmica política da sociedade civil. ${ }^{1}$ As condições institucionais dessa dinâmica, no entanto, merecem ainda ser cuidadosamente analisadas, uma vez que constituem uma das vias de resposta às demandas específicas pela democratização 
das políticas públicas, que as transformações no plano da reforma do Estado têm demandado.

Assiste-se a dois níveis de transformação. Em primeiro lugar, a ampliação do controle social sobre decisões públicas por meio de mecanismos de participação, que envolvem a população diretamente. Os exemplos mais destacados nessa direção têm sido as experiências, no plano local, de orçamentos participativos, mutirões habitacionais, entre outros. Em segundo lugar, o fortalecimento dos mecanismos de controle de política setorial, mediante a criação de instâncias de deliberação e consulta que aglutinam representantes dos interesses diretamente envolvidos, como também de entidades da sociedade civil, provedores de serviços e clientelas. Nesta perspectiva, os conselhos setoriais são uma das formas de constituição de sujeitos democráticos com o propósito de atuar nas políticas públicas, sem anular ou substituir os movimentos de pressão organizados. Enquanto no primeiro caso o princípio fundamental em pauta é a consulta ou o envolvimento direto dos beneficiários na provisão de serviços, no segundo, é a responsabilização dos gestores por decisões e ações implementadas.

Avançar nas questões específicas e contribuir para o debate sobre a emergência dos mecanismos participativos ou de controle social e o seu significado, como determinantes do desempenho da gestão municipal, são o propósito deste artigo. $\mathrm{O}$ trabalho focaliza a instituição das Comissões Municipais de Emprego - CME, criadas como pré-condição institucional para a implantação do Programa de Qualificação Profissional no Estado de Pernambuco, durante o período de 1996 a 2001. A preocupação central é analisar os condicionantes sobre os critérios de preferência, por parte do governo estadual, na homologação dessas comissões, além de procurar desvendar as relações existentes entre tais critérios e a efetivação das ações programáticas. Importante é dizer, no entanto, que ainda há muito que investigar em relação às virtudes e potencialidades dessas instituições, tornando visível a necessidade de estudos e avaliações sobre a sua atuação.

\section{POR QUE VINCULAR OS CONSELHOS GESTORES AO DESEMPENHO DA DESCENTRALIZAÇÃO?}

Partindo do pressuposto de que um Estado descentralizado não pode prescindir de canais de participação, possibilitando que as questões sejam administradas no âmbito da esfera pública, a Constituição de 1988 regulamentou, no país, a participação popular como elemento no processo político. Introduziu-se uma série de mecanismos permitindo que representações de segmentos sociais tivessem acesso ao governo e tomassem decisão sobre alguns problemas públicos, sinalizando para o fato de que a dinâmica social deve exercer uma influência significativa sobre as experiências de formulação e implementação de políticas locais. A abertura de novos canais de comunicação entre os cidadãos e o Estado passou a constituir um instrumento fundamental da gestão pública, evidenciando inusitados aspectos da dinâmica política da sociedade civil. Foi criado, assim, um ambiente propício à inserção dos atores sociais e, além de qualquer princípio ideológico, um fato passou a se impor no panorama brasileiro: a colaboração entre entidades da sociedade civil e órgãos governamentais multiplicou-se, desde a atuação em nível comunitário, até a colaboração em programas sociais. Novas também são a ser as estratégias: as entidades abriram arenas alternativas de intermediação de interesses ao se relacionarem diretamente com a burocracia estatal, quer mediante comissões técnicas e de articulação, a exemplo dos fóruns populares de programas específicos, quer mediante mecanismos de controle social criados a partir de então, como os conselhos gestores nos municípios. Muito embora a criação desses conselhos tenha materializado a proposta do governo federal sobre os pré-requisitos necessários à implantação de um vasto número de políticas sociais, a presença dessas entidades, efetivamente, constitui um traço do perfil político-institucional da descentralização no país, o que bastaria para justificar sua análise. Além disso, são recorrentes questões como: "Quais as leituras possíveis sobre o papel dos conselhos gestores no contexto das políticas sociais?" ou "o que se conhece até então sobre o desempenho ou sobre os resultados e os impactos da atuação dessas instituições?”.

De fato, os conselhos gestores foram a grande novidade nos moldes recentes de formular e implementar políticas públicas no âmbito dos municípios. A experiência brasileira, nesse sentido, é uma das mais expressivas considerando o plano internacional, ${ }^{2}$ ao lado disso, são implantadas práticas exitosas de gestão, entre inúmeros governos municipais. ${ }^{3}$ Entre os fatores determinantes desse êxito, seguramente, estão aqueles vinculados aos resultados e impactos das ações e dos programas nas áreas sociais e, supostamente, aqueles que delineiam a forma mais ou menos centralizada que a gestão assume. A análise da criação e da atuação dos conselhos gestores nos municípios adquire, nesse sentido, uma importância fundamen- 
tal, tanto pela sua potencialidade como mecanismo de controle social quanto pela sua função de compor um modelo de gestão específico.

Nos municípios, os conselhos temáticos têm sido vistos como

um dos principais resultados das recentes reformas municipais, que têm buscado instaurar um regime de ação politica de tipo novo, com uma maior interação entre o governo e a sociedade (GOHN, 2001, p. 83).

Seguindo a mesma argumentação, acredita-se que os conselhos gestores são importantes porque são originários de lutas e demandas populares e de pressões da sociedade civil, a despeito de sua inserção na esfera pública ter sido efetivada por força de lei, de modo integrado a órgãos governamentais vinculados ao poder executivo. A rigor, essa condição não parece se apresentar como impeditivo à composição dos conselhos por legítimos representantes do poder público e da sociedade civil organizada, à sua atuação com responsabilidade nas áreas específicas nem ao controle efetivo das ações públicas setoriais.

Contudo, a instituição dos conselhos gestores, a despeito da quase unanimidade em torno dos efeitos positivos da descentralização decisória, ainda não se firmou, ao menos teoricamente, como um fator de garantia do bom desempenho da gestão. Ou seja, tem-se afirmado que tais experiências se constituem num efetivo fortalecimento da capacidade institucional do município, mas até que ponto essa aptidão representa um patrimônio organizacional capaz de empreender ações coletivas sustentáveis ou se manifesta de modo permutável, circunstancialmente, conforme as singularidades políticas de cada gestão?

A identificação dessa e de outras lacunas analíticas importantes sugere a realização de estudos específicos, sobretudo quando se evidencia a escassez de análises relativas a um conjunto expressivo de experiências, posto que a maioria dos trabalhos se refere a estudos de caso, possibilitando apenas inferências de caráter específico. Nessa mesma perspectiva, as contribuições dos estudos de Gohn $(1990 ; 2001)$ e de outros sinalizam para a necessidade de se aprimorar o foco sobre a atuação dos conselhos gestores, de modo a se extraírem conclusões a respeito de sua efetividade e eficácia. ${ }^{4}$ Seguir essa recomendação, portanto, será uma contribuição importante para o debate sobre o tema.

A preocupação com os condicionantes institucionais sob os quais se dá a prática da gestão pública é manifestada em alguns estudos: sobre o nível de participação e a influência dos atores, nas pesquisas de Draibe (1998) e Melo (2003), entre outros, ou sobre o grau de descentralização obtido por programas sociais em diferentes Estados e as variáveis capazes de influenciar seu comportamento, no trabalho de Arretche (1998). Aliás, a literatura na área de políticas públicas é pródiga na discussão da capacidade institucional, sendo importante, assim, atentar para a diversidade de sentidos que esse conceito vem assumindo no decorrer do tempo. A acepção que se quer privilegiar, aqui, refere-se à construção dessa capacidade em contextos democráticos ou em vias de democratização, tendo como suposto a participação de uma pluralidade de atores e interesses organizados. Nessa perspectiva, as idéias expostas se fundamentam principalmente em paradigmas constitutivos da concepção democrática da participação e têm por base o pressuposto de que a qualidade dessa participação deverá influir decisivamente no grau da democracia constituída.

Nessa mesma linha de argumentação, Pateman (1992) sugere que a depender do tipo de participação (a pseudoparticipação, quando há somente consulta); a participação parcial, só uma parte do fórum participa, e a participação total), níveis distintos de prática democrática serão expressos. Tal distinção é importante posto que a experiência participativa pode resultar, segundo Gohn (2001, p. 44), tanto em cidadãos ativos, politizados, com visão crítica da realidade, conhecedores dos problemas que os circundam, com compreensão sobre as causas e as origens desses problemas, como em cidadãos ativos só na dimensão de tarefeiros, executores de "missões", com atuações individualizadas e personalistas, muito distantes de qualquer sentido público propriamente dito, respaldando-se em éticas e culturas que criam limites à governabilidade.

A rigor, segundo Melo (2003), o grau de eficácia e efetividade no âmbito das ações de um programa ou de uma política setorial depende, fundamentalmente, de algumas condições - enabling conditions - nas quais se mesclam: o nível de legitimidade e representatividade política dos membros; a disponibilidade real de recursos para o setor ou programa envolvido; o grau de socialização das informações (interna e externamente ao conselho ou instância competente para as deliberações); o grau de compromisso com o empowerment (em médio e longo prazos), capaz de superar o efeito conjuntural de ações meramente imediatistas e, por fim, a capacidade de acomodação de conflitos entre os atores envolvidos. 
Em compensação, se existem conclusões sobre a importância da consolidação institucional para o sucesso das ações/interesses do Estado, entre as quais as já referidas são paradigmáticas, há lacunas de conclusões sobre a atuação dessas esferas de participação, como agentes de controle social. Opiniões existem sobre as potencialidades, outros depoimentos sobre limites a sua constituição como um arcabouço institucional efetivo e sustentável. A discussão sobre o desempenho das citadas esferas de participação sugere avaliações, especificamente orientadas a esse objetivo e que extrapolem os estudos de caso. No plano da análise das potencialidades, figuram, favoravelmente, as visíveis estratégias participativas que têm resultado na conquista gradativa dos espaços públicos pelos cidadãos. Um aspecto importante no âmbito dos limites refere-se ao dilema entre o caráter consultivo ou deliberativo das instâncias então criadas. ${ }^{5}$ Contudo, a principal questão no elenco dos limites relaciona-se à identificação dessas instituições nomeadas de instrumentos de controle e participação social, como portadoras de real significado representativo. Remete, por exemplo, à dificuldade de se distinguir, empiricamente, entidades de papel daquelas orgânicas de fato, quando a tradição, a prática e o registro do controle social são ainda embrionários no país. Concorrem para tais suspeitas, principalmente, denúncias sobre ingerências políticas de grupos locais e sobre a criação, a composição e a atuação dos conselhos setoriais. A rigor, é o que se propõe neste artigo: uma análise sobre o curso de instalação das CMEs como atores co-responsáveis pela implementação do Programa Estadual de Qualificação - PEQ no Estado de Pernambuco.

\section{ASPECTOS DESCENTRALIZANTES DO PEQ NO ESTADO DE PERNAMBUCO ${ }^{6}$}

O PEQ é um programa de capacitação profissional realizado com recursos do FAT, sob a responsabilidade do Ministério do Trabalho e das secretarias setoriais competentes em cada Estado. Trata-se de uma terceirização de ações, para a realização de cursos, por entidades executoras contratadas pelo governo do Estado. O PEQ foi implantado em Pernambuco em 1996 de acordo com as exigências federais do Planfor e executado durante duas gestões administrativas do governo estadual. A alocação municipal dos recursos para a capacitação foi feita com base no cálculo estimado do percentual de treinandos a ser atendido, definido proporcionalmente à composição da PEA municipal no Estado.
O programa contou com princípios fundamentais estabelecidos com o intuito de promover uma descentralização das ações, que no Estado de Pernambuco caracterizou-se por uma permanente expansão, desde sua implantação. O primeiro fator relevante refere-se ao crescimento da quantidade de indivíduos atendidos anualmente, aliado ao maior número de municípios contemplados com os cursos de qualificação e formação profissional. Em 1996, o programa atendeu 43 mil inscritos e em 2001 já atingia 174.400 treinandos. A quantidade de municípios atendidos subiu de 44, em 1996 (ano de implantação do programa) para 184, em 1998 (final da primeira gestão em que o programa foi realizado). A segunda gestão também foi marcada por uma evolução no atendimento: de 122 municípios em 1999, para 161 em 2001 , equivalente a $87,1 \%$ do total (185) de municípios do Estado. ${ }^{7}$

Para os propósitos deste estudo, mais do que a evolução do número de municípios atendidos, é interessante observar a evolução das homologações das CMEs, que têm por atribuição principal elaborar o plano de trabalho - PT, portador das diretrizes da qualificação nos municípios. $\mathrm{Na}$ perspectiva de auxiliar na elaboração dos PTs, a secretaria estadual ${ }^{8}$ encaminhava, para as CMEs, a relação de projetos apresentados pelas entidades executoras e a planilha de pré-seleção técnica dos cursos, elaborada para cada município, na qual se explicitava também o quadro da demanda não-atendida. A principal fonte de informações sobre as necessidades dos municípios está contida, assim, nos planos de trabalho elaborados pelas CMEs, que têm uma composição tripartite, reunindo três representantes do governo municipal e estadual, três membros que formam a bancada dos empregadores e três outros representantes de setores da sociedade civil. Uma vez completado o período de mandato dos seus representantes, ou havendo eleição e posse dos novos prefeitos, a composição das CMEs é alterada.

Para cada ano era estabelecido um prazo para o envio dos planos de trabalho das CMEs e, a rigor, muitas delas não cumpriam esse prazo, o que atrasava o processo de seleção técnica dos cursos, em alguns anos. As CMEs, então, definiam suas preferências e encaminhavam os relatórios à secretaria estadual. A partir disso era feito um ajuste entre a oferta (por parte das entidades) e a deman$d a$ (por parte das CMEs). Com vista à tomada de decisão final, eram realizadas reuniões também com a CME.

A despeito de o PEQ ter sido implantado no Estado de Pernambuco em 1996, o processo de criação e homologa- 
ção das CMEs foi paulatino. Dos 185 municípios, 128 possuíam CME até dezembro de 2001, ao passo que apenas 37 CMEs foram homologadas até 1997. Quanto ao envio dos planos de trabalho, também ocorreu uma evolução lenta, mas em 2001 já foi expressivo - das 128 CMEs instaladas e homologadas, 106 enviaram os PTs, embora muitas delas o tenham feito fora do prazo estipulado.

Especificamente no Estado de Pernambuco, o PEQ revelou um alto grau de capilaridade entre as distintas microrregiões, muito embora tenha se evidenciado uma diferenciação microrregional na proporção de municípios que conseguiram instalar a CME, como demonstra a tabela a seguir. Esse fato aparece como um elemento para a construção de hipóteses sobre a captura e a manipulação do PEQ, como em outros programas sociais, por grupos que estão no poder.

TABELA 1

Comissões Municipais de Emprego - CME Homologadas, segundo Região de Desenvolvimento Pernambuco - 1997-01

\begin{tabular}{lcccccc} 
& & \multicolumn{6}{c}{ Números Absolutos } \\
\hline $\begin{array}{l}\text { Região de } \\
\text { Desenvolvimento }\end{array}$ & $\begin{array}{c}\text { Total de } \\
\text { Municípios }\end{array}$ & 1997 & 1998 & 1999 & 2000 & 2001 \\
\hline Total & 185 & 37 & 49 & 76 & 112 & 128 \\
$\begin{array}{l}\text { Região Metropolitana } \\
\text { de Recife }\end{array}$ & 14 & 8 & 10 & 11 & 13 & 14 \\
Mata Norte & 19 & 6 & 6 & 10 & 13 & 15 \\
Mata Sul & 24 & 6 & 9 & 11 & 18 & 19 \\
Agreste Setentrional & 19 & 5 & 5 & 8 & 11 & 13 \\
Agreste Central & 26 & 4 & 5 & 8 & 15 & 17 \\
Agreste Meridional & 26 & 1 & 2 & 4 & 7 & 11 \\
Sertão do São Francisco & 8 & 1 & 1 & 3 & 6 & 8 \\
Sertão do Araripe & 10 & 1 & 1 & 6 & 7 & 7 \\
Sertão do Pajeú/Moxotó & 24 & 5 & 8 & 10 & 14 & 15 \\
Sertão Central & 8 & 0 & 1 & 2 & 3 & 3 \\
Sertão de Itaparica & 7 & 0 & 1 & 3 & 5 & 6 \\
\hline
\end{tabular}

Fonte: Agência do Trabalho/Seplandes.

Um aspecto que complementa o quadro da descentralização é a ampliação da rede de entidades de educação profissional com intuito de diversificar as possibilidades metodológicas e técnicas dos cursos oferecidos, além de desconcentrar o atendimento, que no início do programa estava bastante limitado a dez instituições, entre as quais havia apenas uma ONG. De acordo com as diretrizes do Planfor, o segmento das ONGs foi cada vez mais inserido nas ações do programa, passando, em 2001, a constituir
55 entidades, representando $67 \%$ da rede de educação profissional envolvida com o PEQ no Estado. A orientação do Planfor para que as instituições do terceiro setor fossem priorizadas na escolha das entidades foi justificada pelo fato de as ONGs apresentarem maiores chances de proporcionar cobertura espacial em regiões inóspitas e possuírem maior agilidade e flexibilidade institucional. Afora isso, as ONGs podem incorporar ao programa outros setores representativos da sociedade através de diversas categorias profissionais envolvidas nos trabalhos. O contraponto a esse aspecto, além da dificuldade de controle público sobre o nível de competência técnica e organizacional dessas instituições, é um possível reforço à hipótese de captura do programa por parte de grupos privilegiados, capazes de ingerência política sobre as CMEs na perspectiva de garantir a oferta de cursos específicos ou a manutenção de clientelas cativas. Por mais essa razão, os objetivos deste trabalho estão norteados pela busca de respostas a uma expectativa existente no senso comum sobre a captura e manipulação de programas sociais por grupos que estão no poder.

\section{O MODELO ANALÍTICO ADOTADO}

Fica claro até aqui que no âmbito da esfera políticoinstitucional, na qual se implementou o PEQ, a presença e a atuação das CMEs passaram a ser variáveis centrais. Para os propósitos deste estudo, foi necessário construir um modelo analítico (COUTINHO, 2003) que considerasse a possibilidade de o PEQ em Pernambuco estar sujeito à ingerência política por parte daqueles que fazem parte da aliança - governo estadual e elites locais - quando da realização dos cursos e da distribuição dos recursos no Estado. Responder a essa questão tornou-se fundamental para avaliar a capacidade institucional do programa, uma vez que este, ao ser construído sob uma lógica de descentralização da gestão pública, deveria estar impermeável a esse tipo de ação e a tais interesses. Construíram-se então duas hipóteses.

\section{Hipótese 1}

As variáveis de aliança política entre o poder local e o estadual apresentam uma correlação positiva e significante com a homologação de comissões municipais de emprego no Estado. As comissões foram homologadas preferencialmente nos municípios onde o poder local está alinhado ao governo estadual. 
Esta primeira hipótese buscou detectar o processo político que norteou a homologação das comissões de emprego nos municípios. Isto é, pareceu lógica a suposição de que os municípios aliados ao governo estadual seriam priorizados no curso da homologação das suas comissões, inclusive com objetivos de caráter eleitoral, uma vez que mediante a instalação da CME obter-se-ia maior visibilidade pública.

\section{Hipótese 2}

A aliança política entre o governo municipal e o estadual teve um efeito positivo e significante na alocação dos recursos para os municípios em 2001 e, conseqüentemente, no atendimento da demanda de inscritos.

Esta hipótese tem como objetivo principal verificar se os municípios contemplados com o programa e aliados ao governo estadual recebem mais recursos e conseqüentemente apresentam uma quantidade maior de inscritos. Acredita-se que quanto maior o universo atingido por determinado programa público, maior será a possibilidade de angariar dividendos políticos, por parte das elites locais e mesmo estaduais. No caso da negação desta hipótese, verifica-se o esforço para construir a institucionalidade do programa, de acordo com as diretrizes descentralizadoras, fundadas na priorização dos municípios que apresentem a CME instalada.

Para testar as hipóteses de trabalho foi necessário instituir indicadores que representassem os "interesses políticos", mediatizados pela aliança entre o poder local e o estadual, buscando verificar o poder explicativo desta variável sobre a homologação das comissões e sobre a presença ou não de cursos de capacitação nos municípios. Para o modelo analítico foram considerados como aliados automáticos do poder local e do governo estadual, em 1997 e 1998, os partidos que em 1996 apoiavam a coligação que vencera as eleições estaduais em 1994: PSB, PDT, PC do B e PPS. Em 2000, foram considerados os partidos que participaram da aliança estadual vencedora das eleições de 1998: PFL, PMDB, PPB e PSDB. ${ }^{9}$ Esse arranjo, obviamente, apresenta problemas porque nos municípios as composições partidárias nem sempre obedecem à determinação das executivas estadual e nacional dos partidos. Em muitas situações as escolhas políticas são geradas pelo personalismo, pelos interesses de elites locais, patrimonialismo e outros fatores. Essas situações são extremamente complexas de se mensurar e para tal seria preciso estudar caso a caso para determinar o padrão de aliança local, o que não é proposta deste estudo.

Ante a complexidade de mensurar os efeitos reais desses tipos de fatores, segundo a orientação das hipóteses, em uma análise bivariada, optou-se por uma investigação baseada em modelos multivariados, capazes de testar as relações entre o alinhamento político dos municípios com o governo estadual e as homologações de comissões municipais e, ainda, a relação entre o alinhamento político e a alocação dos recursos do programa no Estado. Para tanto foi utilizada a base de dados da avaliação externa realizada para o Planfor, referente a 2001, acrescida das informações de Sefaz, IBGE, Seplandes e TRE.

A metodologia consistiu em módulos de análise seqüenciados e diferenciados pela técnica estatística utilizada. O universo estudado incluiu 184 municípios do Estado de Pernambuco para o exame das homologações e para o modelo de regressão linear múltipla. A análise para o teste da hipótese 1, sobre a relação entre a homologação de CMEs e a aliança dos municípios com o governo estadual, foi realizada através de proporções entre essas duas variáveis. Para isso foi feito um registro para cada ano do programa, entre 1997 e 2001. Eliminaram da amostra os municípios que já dispunham de comissão homologada no ano anterior para não causar um efeito indesejado no ano subseqüente, visando a minimizar o efeito causado pelo tamanho da base governista, que sempre foi mais que o dobro do conjunto dos municípios oposicionistas nos anos estudados.

Para testar a hipótese 2, sobre a relação entre a alocação dos recursos e o alinhamento político do município com o governo estadual, foi elaborado um modelo de regressão linear múltipla, no qual a variável dependente é o logaritmo neperiano dos recursos recebidos e as variáveis independentes são: a população dividida por mil habitantes; a presença no município de comissão homologada ou não por ano de homologação (variável dicotômica - set de dummies) e o alinhamento político do governo do município com o estadual ou não em 1998 (variável dicotômica). A população funciona como variável de controle no modelo, referente às diferenças de porte dos municípios; a homologação por ano aparece como uma variável de percepção da importância do nível de institucionalização do programa, enquanto o alinhamento mostra o peso da ingerência política do governo do Estado na distribuição dos recursos, no âmbito do PEQ. 


\section{RELAÇÃO DO ALINHAMENTO POLÍTICO DO MUNICÍPIO COM O PODER ESTADUAL}

\section{Homologação das Comissões Municipais de Emprego entre 1997 e 2001}

Em relação à primeira hipótese foram utilizadas duas variáveis: o ano de homologação da $\mathrm{CME}$ e a variável dicotômica aliado (valor um) e não-aliado (valor zero) do governo estadual. Depois, foi realizado um cruzamento dessas duas variáveis para detectar a diferença da proporção entre ser aliado e não-aliado do governo estadual na homologação das CMEs ao longo dos anos de execução do programa.

\section{TABELA 2}

\begin{tabular}{|c|c|c|c|}
\hline \multirow[b]{2}{*}{ Ano } & \multicolumn{3}{|c|}{ Municipios que Formaram CME } \\
\hline & $\begin{array}{c}\text { Total } \\
\text { (Números Absolutos) }\end{array}$ & $\begin{array}{c}\text { Situação de Aliança } \\
\text { Política com o } \\
\text { Governo Estadual }\end{array}$ & $\begin{array}{c}\text { Total } \\
(\%)\end{array}$ \\
\hline \multirow[t]{2}{*}{997} & 37 & Aliado & 11,0 \\
\hline & & Não-Aliado & 6,0 \\
\hline \multirow[t]{2}{*}{998} & 49 & Aliado & 14,0 \\
\hline & & Não-Aliado & 12,0 \\
\hline \multirow[t]{2}{*}{999} & 76 & Aliado & 18,0 \\
\hline & & Não-Aliado & 24,0 \\
\hline \multirow[t]{2}{*}{000} & 112 & Aliado & 38,0 \\
\hline & & Não-Aliado & 30,0 \\
\hline \multirow[t]{2}{*}{001} & 128 & Aliado & 31,0 \\
\hline & & Não-Aliado & 30,0 \\
\hline
\end{tabular}

Fonte: TRE; Agência do Trabalho.

Os resultados obtidos não confirmam a hipótese de ingerência política na homologação das comissões, posto que a diferença da proporção na formação das CMEs entre os partidos da base aliada não é representativa (o mesmo ocorre inversamente entre os não-aliados). Além disso, em todos os anos analisados se oferece um padrão pouco consistente no comportamento, exceto em $1999 \mathrm{em}$ que a diferença se inverteu em favor dos não-aliados. Como pode se perceber, a linha de aliados e a de não-aliados ao governo estadual não são suficientemente próximas e não são tão diferentes para que se possa estabelecer um padrão para determinar a formação das CMEs com os dados aqui disponíveis. Isso fica evidenciado no Gráfico 1.
GRÁFICO 1

Municípios que Formaram Comissões Municipais de Emprego - CME, segundo Situação de Aliança Política com o Governo Estadual Pernambuco - 1997-01

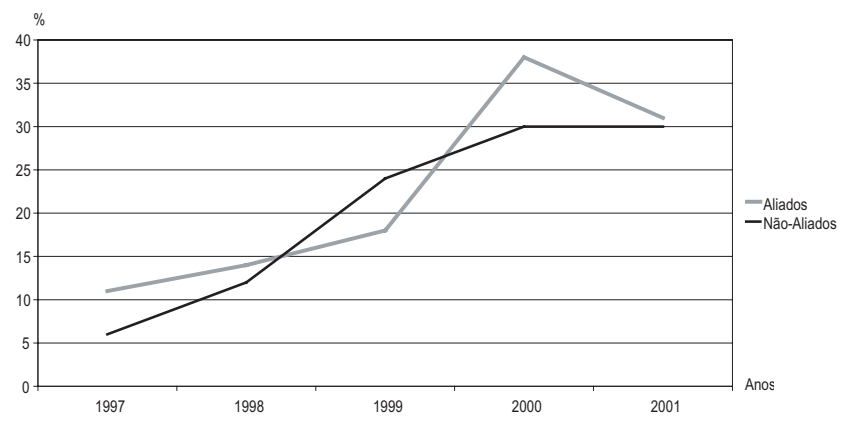

Fonte: Coutinho (2003).

\section{Alocação dos Recursos do Programa para 2001}

O teste do efeito entre o alinhamento político nos municípios e os recursos alocados permitiu verificar se a distribuição dos recursos do programa foi feita de acordo com a recomendação técnica ou se existiu alguma variação que indicou ingerência ou ação política no sentido de canalizar recursos para determinado município da base aliada.

\section{VARIÁVEIS DO MODELO}

Variável Dependente:

- Recursos Alocados: foi extraído o logaritmo da variável recurso por município, eliminando-se os problemas de heterocedasticidade, bastante comuns em variáveis representativas de renda ou que envolvem recursos.

Variáveis Independentes:

- Aliança com o governo estadual: variável dummy contendo o valor um para os aliados e zero para os não-aliados. Esta variável foi construída a partir dos dados do TRE dos pleitos estaduais de 1994 e 1998 e dos municipais de 1996 e 2000.

- População dividida por mil (pop/mil): variável de controle espacial e populacional, cujos dados têm como fonte o IBGE. Sua função é verificar se a importância econômica e social dos municípios está sendo respeitada na distribuição dos recursos, ou seja, se existe uma adequação mínima à demanda.

- Ano de homologação da CME: foram utilizados um set de dummies para comparar cada ano de homologação no 
período de 1997-2001 e, como categoria de referência, os municípios que não tinham CME homologada em 2001. Esta variável foi construída com os dados obtidos na secretaria estadual para medir o grau de institucionalização e burocratização do programa. Para municípios com CME instalada esperava-se uma maior alocação de recursos em relação àqueles que não a possuíam; além disso, buscouse medir se o tempo de instalação da CME apresentava alguma importância nessa alocação.

\section{INTERPRETAÇÃO DO MODELO E DOS RESULTADOS OBTIDOS}

O modelo analítico testado apresentou um excelente índice de explicação para os dados em questão. $\mathrm{O} \mathrm{R}^{2}$, ou seja, o poder explicativo do modelo, dado pelo porcentual da variância explicada, é de 59,7\% dos dados.

Quanto ao comportamento das variáveis trabalhadas, nota-se que a variável "POP/MIL" apresentou significância expressiva, tendo para cada mil habitantes um acréscimo correspondente de $0,3 \%$ nos recursos recebidos pelos municípios, indicando uma boa distribuição entre as populações-alvo.

A variável "alinhamento político com o governo estadual em 2000" (Aliado 2000) não apresenta significância, uma vez que o valor da probabilidade do teste " $t$ " é de 0,41 ou $41 \%$, sendo o valor máximo admitido nesse tipo de estudo de 0,05 ou $5 \%$. Essa análise permite afirmar que a variável "Aliado 2000" não representa um elemento capaz de confirmar a hipótese de que o alinhamento político interfere na alocação dos recursos do programa dentro do modelo. Sendo assim, aceita-se a hipótese nula não influência dos agentes políticos na alocação dos recursos para o ano de 2001, indicando que esses recursos seguem a lógica institucional, sendo aportados de acordo com o estabelecido pelas metas do programa. Isso sugere que o programa atingiu, ao menos em uma análise preliminar com os dados disponíveis, um certo grau de institucionalização dos recursos no ano pesquisado.

O fato de haver comissões formadas desde 1997 (H1997) aumenta em até $441 \%$ o volume de recursos por habitante em relação aos municípios que não têm CME instalada, mesmo controlando o tamanho do município e supondo-se que cidades maiores têm uma maior capacidade institucional. Isso denota que os municípios que primeiro buscaram a institucionalização por meio da implantação da Comissão Municipal de Emprego, agindo dentro da nova lógica de gestão pública voltada para descentralização, obtiveram ganhos significativos no volume e na probabilidade de receberem recursos do programa, pelo menos em relação àqueles municípios que não formaram comissões e serviram de padrão comparativo no modelo.

Seguindo essa tendência, a presença de comissões formadas desde 1998 (H1998) aumenta em até 445\% o volume de recursos por habitante, em relação aos municípios que não apresentam CME instalada. Já a presença de comissões formadas desde 1999 (H1999) aumenta em até $234 \%$ o volume de recursos por habitante, em relação aos

\section{Resumo do Modelo}

\begin{tabular}{|c|c|c|c|c|c|c|}
\hline $\begin{array}{c}\text { Modelo } \\
1 \\
\end{array}$ & $\begin{array}{r}\text { Coeficie } \\
0,7 \varepsilon \\
\end{array}$ & & $\begin{array}{c}\mathrm{R}^{2} \text { Ajustado } \\
0,597 \\
\end{array}$ & & $\begin{array}{l}\text { Erro Padrão Estimado } \\
\qquad 0,86328\end{array}$ & \\
\hline & $\begin{array}{c}\text { Valor do } \\
\text { Coeficiente - B }\end{array}$ & Exponencial & $\begin{array}{c}\text { Efeito } \\
(\%)\end{array}$ & $\begin{array}{c}\text { Erro } \\
\text { Padrão }\end{array}$ & Beta & Significância \\
\hline Constante & 9,03 & 8386,45 & & 0,18 & & 0,00 \\
\hline Aliado 2000 & $-0,12$ & 0,89 & $-11,05$ & 0,14 & $-0,04$ & 0,41 \\
\hline H1997 & 1,69 & 5,41 & 441,09 & 0,26 & 0,39 & 0,00 \\
\hline H1998 & 1,70 & 5,46 & 445,73 & 0,24 & 0,43 & 0,00 \\
\hline H1999 & 1,21 & 3,34 & 234,43 & 0,22 & 0,34 & 0,00 \\
\hline $\mathrm{H} 2000$ & 1,21 & 3,37 & 236,99 & 0,20 & 0,39 & 0,00 \\
\hline $\mathrm{H} 2001$ & 0,68 & 1,98 & 97,54 & 0,23 & 0,17 & 0,00 \\
\hline População/Mil & 0,0001 & 1,00 & 0,31 & 0,00 & 0,29 & 0,00 \\
\hline
\end{tabular}


municípios que não dispõem de CME instalada, sendo de $237 \%$ em 2000 (H2000) e de 97\% em 2001 (H2001), quando comparados aos municípios sem CME.

Além de se observar uma grande diferença entre 199798, com relação a 1999-00, referente à mudança políticoinstitucional introduzida pelo novo governo, ressalta-se também um fator de redução progressiva da quantidade de homologações/ano com o passar do tempo. Do mesmo modo, o efeito (porcentual) vem caindo a cada ano por que os municípios que homologaram sua CME mais recentemente estão menos preparados de forma institucional para receber os cursos e captar os recursos do programa. Esta evidência fortalece a hipótese de o PEQ estar se consolidando cada vez mais e sua institucionalidade ao longo do tempo assumir um formato cada vez mais delineado.

$\mathrm{Na}$ verdade o modelo demonstrou ser robusto no sentido de verificar estatisticamente o que se percebe por meio das teorias e das análises dos relatórios de avaliação: o programa em Pernambuco está razoavelmente consolidado de forma institucional, de acordo com os dados de 2001, e a aliança política com o governo estadual não representou vantagem significante na alocação dos recursos do programa.

O modelo tem a virtude de demonstrar que o tamanho dos municípios é uma variável importante (POP/MIL) e considerada pelos gestores do programa, uma vez que fica evidenciado que quanto maior a população municipal maior será a quantidade de recursos. Isso é importante do ponto de vista estratégico, a fim de evitar que municípios com muitos habitantes recebam relativamente menos recursos. Trata-se de mais um indicativo do grau de institucionalização do programa, que permite ao analista de políticas públicas mapear a coerência na distribuição orçamentária comparando-se os recursos alocados com a população do município.

\section{CONCLUSÕES}

$\mathrm{Na}$ análise apresentada, importou examinar se houve uma diretriz política para os critérios de preferência nas homologações das CMEs, de acordo com a estratégia do governo estadual em Pernambuco, ao mesmo tempo em que se procurou investigar se esse seria um fator que deporia contra a institucionalização do programa.

A oportunidade desta análise se deve ao fato de que o Programa de Qualificação Profissional se encontra descentralizado espacialmente em muitos Estados. Em Pernam- buco, o PEQ vem sendo implementado em todas as Regiões de Desenvolvimento e na maior parte dos municípios. Em 2003, já existiam 150 CMEs homologadas. Aferir as condições políticas nas quais tais comissões foram instaladas é muito importante, no sentido de agregar elementos analíticos sobre a institucionalização do programa e a estabilização dessa política pública em Pernambuco. Além disso, questões sobre a lógica de alocação de recursos ganham destaque quando se focaliza a efetividade dos programas sociais: se o executado corresponde ao previsto pelo programa ou à capacidade institucional instalada no município (no caso, a presença e a atuação da CME).

Com o teste da primeira hipótese de trabalho, a relação entre "ser da base de apoio do governo" e a "preferência na homologação das comissões" não foi confirmada, visto que no período de 1996 a 2001 não foi possível identificar um padrão coerente entre o alinhamento político com o governo estadual e a homologação de comissões municipais. Tal constatação pode contar com diversas fontes de explicação, até mesmo um certo descaso no início do programa, dado ao desconhecimento sobre os lucros políticos para o governo estadual que um programa desse tipo poderia auferir. No segundo ano o programa foi estendido a mais de $99 \%$ dos municípios, quando na época apenas $22 \%$ deles possuíam comissões municipais.

Isso indica que nos três primeiros anos o programa funcionou segundo a lógica supply-driver, não havendo preocupação com a demanda, uma vez que não havendo comissão municipal inexistiam planos de trabalhos de acordo com as necessidades ou as vocações econômicas. Tal fato conferia uma conotação de pouca institucionalização ao programa, apesar de ele estar extremamente descentralizado territorialmente e atender praticamente todo o Estado. Significa dizer que a distribuição espacial do programa não serve, isoladamente, como um indicador de descentralização e institucionalização. Daí a opção tomada de verificar se a distribuição dos recursos estava de acordo com o porte dos municípios (população, desenvolvimento econômico, etc.) e se o programa estava sendo devidamente institucionalizado, mediante a atuação das CMEs garantindo uma certa lógica demand-driver para o PEQ.

Contudo, com a não-confirmação da primeira hipótese de trabalho, não se deve simplesmente desconsiderar a ocorrência de influências e ingerências de atores com interesses privados e de integrantes da base governista. Estes interesses apenas não se refletiram diretamente na homologação das comissões. 
Com relação à segunda hipótese é importante uma análise mais refinada para responder principalmente a duas questões fundamentais: a primeira consistiu em verificar se a distribuição de recursos e cursos foi realizada de acordo com critérios não-políticos, ou seja, independentemente de o município pertencer à base aliada ao governo estadual, a alocação obedece a critérios técnicos do programa? A segunda questão buscou analisar a distribuição dos recursos seguindo os critérios de importância econômica dos municípios. Isso pôde ser aferido com a utilização do tamanho da população de cada município - uma variável de controle no modelo de regressão linear múltipla - para eliminar o efeito esperado causado pela diferença econômica e populacional dos municípios, na perspectiva de obter o efeito preciso da variável "alinhamento político com o governo estadual" sobre a distribuição dos recursos.

A conclusão obtida sugere que aqueles municípios que se preocuparam com as exigências institucionais mais cedo exibiam maior probabilidade de receber os recursos do que aqueles que não buscaram a institucionalização do programa. Em outras palavras, a descentralização e a existência de CME são condicionantes não só para a implantação do programa como também para a alocação de seus recursos. A análise do modelo aqui apresentada, de suas variáveis e dos efeitos destas sobre os trâmites do programa permitiu que fosse comprovado estatisticamente, observando-se os dados de 2001, que a institucionalidade do PEQ em Pernambuco apresentou um grau desenvolvido de implementação e consistência.

Não se pretende com isso afirmar que as elites políticas e os interesses específicos e privados tradicionais na política pernambucana estão alijados desse processo e que tal política pública estaria "blindada" contra esse tipo de ação, na qual o tecido institucional do programa seria impermeável à ação de agentes externos capazes de direcionar e manipular os recursos e as ações do PEQ. Provavelmente existem situações nas quais os interesses políticos de atores ligados ao poder estadual direta ou indiretamente ainda são capazes de interferir no processo de forma concreta e até mesmo pressionar e/ou influenciar membros das comissões municipais e estaduais como parte de uma estratégia traçada para objetivos eleitorais e de manutenção de espaços políticos. O programa em Pernambuco, segundo os dados de 2001, atingiu uma situação na qual é possível afirmar que está sendo construído um arcabouço institucional pautado na focalização da demanda, pelo qual os cursos serão oferecidos de acordo com necessidades e realidades específicas dos municípios. A discussão sobre a atuação das CMEs ganha, no entanto, cada vez mais urgência, posto que tais instâncias, por motivos diversos, apresentam ainda dificuldades de realizar tarefas no âmbito das competências previstas pelo programa: o levantamento das demandas; a elaboração adequada dos planos de trabalho; o acompanhamento dos programas e o encaminhamento ao mercado de trabalho.

A conclusão mais importante deste estudo é que os atores que são representados pela elite local e pela figura do prefeito (como membro dessa elite ou representante político dela) tiveram que renovar suas estratégias de ação, uma vez que o arcabouço institucional montado para executar o Programa de Qualificação Profissional, norteado por modelos descentralizados, acabou por dificultar a ação na sua condição mais tradicional. A conclusão de que a distribuição dos cursos e dos recursos vem obedecendo a critérios não-políticos no Estado denota a existência de uma institucionalidade latente no âmbito desta política em Pernambuco.

\section{NOTAS}

1. Alguns estudiosos no Brasil têm se dedicado ao tema da participação sociopolítica, com uma contribuição relevante. Destaque-se Gohn (1990, 1997 e 2001), Pateman (1992), Souza (1997 e 2000), Andrade (1996a; b) e mais recentemente Melo (2003).

2. Estudos promovidos pela Universidade de Birmingham, no âmbito do projeto Urban Governance, Partnerships and Poverty, realizado entre 1999 e 2000, analisaram casos comparativos na Ásia, África e América Latina, sugerindo que vem ocorrendo uma verdadeira revolução institucional na última década, sinalizada pela criação de centenas de conselhos nas esferas locais.

3. A Fundação Getúlio Vargas, por meio de seu Programa Gestão Pública e Cidadania, tem acompanhado o surgimento de experiências exitosas no que se refere à participação da sociedade na gestão e, entre estas, as estratégias de redução da pobreza têm sido recorrentes.

4. A partir de análises não-sistemáticas, alguns aspectos da atuação de conselhos gestores já podem ser conhecidos: por exemplo, a opinião de 206 membros de Comissões Municipais de Emprego, sobre a articulação com o poder público no Programa de Qualificação Profissional, foi levantada, em 2002, como parte da avaliação externa do PEQ 2001 em Pernambuco, realizada pelo Núcleo de Opinião e Políticas Públicas - Neppu, da Universidade Federal de Pernambuco.

5. Ver Andrade (1996b) sobre o discurso da participação e a atuação dos Conselhos Gestores Municipais.

6. As informações que serviram de base às presentes considerações foram levantadas durante os trabalhos da avaliação externa do Programa Estadual de Qualificação no Estado de Pernambuco, realizadas pelo Núcleo de Opinião e Políticas Públicas - Neppu, da Universidade Federal de Pernambuco, para 2000, 2001 e 2002. Especificamente, registra-se a participação em reuniões ordinárias da Comissão Estadual de Emprego, nos seminários das CMEs, realizados em fevereiro de 2001 e abril de 2002, além da aplicação de questionários em 82 CMEs instaladas até 2001 . 
7. Fonte: Secretaria de Planejamento e Desenvolvimento do Estado de Pernambuco.

8. Foi criada, no âmbito da Secretaria Estadual de Planejamento e Políticas Sociais, a Agência do Trabalho, com a competência de coordenar o PEQ no Estado de Pernambuco.

9. Dados extraídos dos arquivos do Tribunal Regional Eleitoral.

\section{REFERÊNCIAS BIBLIOGRÁFICAS}

AFFONSO, R.B.; SILVA, P.L.B. (Org.). Descentralização e politicas sociais. São Paulo: Unesp/Fundap, 1996, 6 v.

ANDRADE, I.A.L. de. Descentralização e Poder Municipal no Nordeste: os dois lados da nova moeda. In: XX Encontro Nacional da Anpocs. GT de Políticas Públicas. Caxambu, 1996a.

Políticas e Poder: o discurso da participação. São Paulo: AD Hominem; Natal: Cooperativa Cultural da UFRN, 1996b.

ARRETCHE, M. Políticas Sociais no Brasil: descentralização em um Estado Federativo. Revista Brasileira de Ciências Sociais, n. 40, v. 14, p. 111-141, 1999.

O processo de descentralização das politicas sociais e seus determinantes. Tese (Doutorado) - Unicamp, Campinas, 1998.

Mitos da descentralização: mais democracia e eficiência nas políticas públicas? Revista Brasileira de Ciências Sociais, n. 31, ano XI, p. 44-66, 1996.

BANCO MUNDIAL. Más Allá del Centro: la descentralización del Estado. Estudios del Banco Mundial sobre América Latina y Caribe. Puentos de vista. Washington, D.C., 1999.

BORJA, J. A participação citadina. Espaço e Debates, São Paulo, Cortez, n. 24, 1988.

CARVALHO, A.I. Conselhos de Saúde no Brasil: participação cidadã e controle social. Rio de Janeiro: Ibam/Fase, 1995.

CEPAM. Conselhos municipais das áreas sociais. Informativo Cepam, São Paulo, Fundação Prefeito Faria Lima, n. 1, 1999.

COUTINHO, H. O processo de descentralização e o Programa Estadual de Qualificação Profissional em Pernambuco: a homologação das Comissões Municipais de Emprego. Dissertação (Mestrado em Ciência Política) - da Universidade Federal de Pernambuco, Recife, 2003.

DALLARI, D. O que é participação politica? São Paulo: Brasiliense, 1984.

DRAIBE, S. A nova institucionalidade do sistema brasileiro de politicas sociais: os conselhos nacionais de políticas setoriais. Campinas: Nepp/Unicamp, 1998.

GOHN, M. da G. Conselhos gestores e participação sociopolitica. São Paulo: Cortez, 2001. (Coleção Questões da nossa época, v. 84).
Teoria dos Movimentos Sociais. São Paulo: Loyola, 1997.

Conselhos Populares e participação popular. Serviço So-

cial \& Sociedade, São Paulo, Cortez, v. IX, n. 26, p. 25-47, 1990. Participação Popular e Estado. Tese (Doutorado) - Universidade de São Paulo, São Paulo, 1983.

LUBAMBO, C.; GUIMARÃES, S. O Prezeis: uma estratégia de ação coletiva para uma conquista social. In: ABONG. O impacto social do trabalho das ONGs no Brasil. São Paulo: 1998.

LUBAMBO, C. Descentralização: a experiência das ONGs na formulação de políticas públicas na cidade do Recife. Caderno de Estudos Sociais, Recife: Ed. Massangana, v. 16, n. 1, jan./jun. 2000, FJN.

O desempenho da gestão pública e seus determinantes: uma análise em municípios do Nordeste. Tese (Doutorado) - Universidade Federal de Pernambuco, Recife, 2000.

MELO, M.A.B.C. de. Empowerment e Governança no Brasil: questões conceituais e análise preliminar de experiências selecionadas. Background paper. World Bank - Brazilian Office Draft, 2003.

Crise federativa, guerra fiscal e hobbesianismo municipal: efeitos perversos da descentralização? São Paulo em Perspectiva, São Paulo, Fundação Seade, v. 10, n. 3, p. 11-20, 1996.

PATEMAN, C. Participação e Teoria Democrática. Rio de Janeiro: Paz e Terra, 1992

PROGRAMA DE LAS NACIONES UNIDAS PARA EL DESARROLLO; BANCO INTERAMERICANO DE DESARROLLO. El Capital Social (Hacia la construcción del Índice de Desarrollo Sociedad Civil de Argentina). Buenos Aires: Edilab Ed., 1988.

SOUZA, C. Strengthening democracy at the grass-roots: recent trends in local government and civil society in Brazil. In: Confronting the Challenges to Democracy in the 21 st Century, 2000. São Paulo. Confronting the Challenges to Democracy in the 21 st Century, 2000 .

Constitutional Engineering in Brazil: The Politics of Federalism and Decentralization. New York: St. Martin's Press, 1997. $211 \mathrm{p}$.

Cátia W. Lubambo: Doutora em Sociologia pela Universidade Federal de Pernambuco, Pesquisadora da Fundação Joaquim Nabuco e do Núcleo de Opinião e Políticas Públicas no Departamento de Ciência Política da Universidade Federal de Pernambuco (lubambo@fundaj.gov.br).

Henrique G. Coutinho: Mestre em Ciência Politica pela Universidade Federal de Pernambuco, Pesquisador do Núcleo de Opinião e Políticas Públicas no Departamento de Ciência Política da Universidade Federal de Pernambuco (henriqueguima@hotmail.com). 